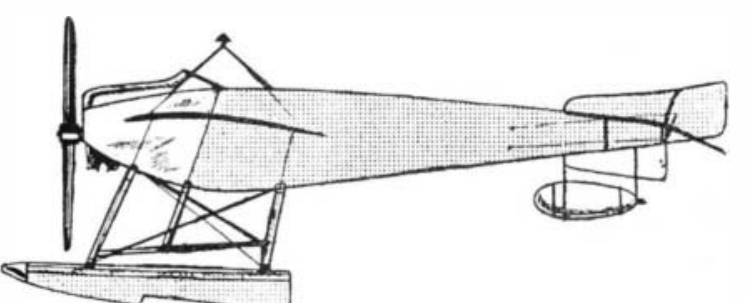

The 100 Horse-power Nieuport Hydro-monoplane.

the Hanriot monoplane. All praise to them! NIEUPORT.

Four machines are shown on this stand-a standard 28 horse-power Nieuport monoplane of the school type, a standard 70 horse-power two-seater, a new racing model, and a 100 horse-power. "Hydravion," similar in every respect to the one that hangs suspended from the roo above the exhibit of the French Minister of War. No special description of the first two models is necessary. They are quite standard; and, for that matter, very little need be said of the last two, for in the case of the racing model the machine is simply a smaller edition of the standard machine with changes in the chassis, and, for standard machine with changes in the chassis, and, for
the Hydravion, it is but the ordinary 100 horse-power three-seater model with a float chassis instead of a wheeled one.

Let us first deal with the racing model. To attain high speed the designer has not resorted to high engine power. He has kept to the 50 horse-power Gnome, and to increase the speed has aimed at still further increasing to increase the speed has aimed at still further increasing
the efficiency of the machine by cutting down head resistance.

This is chiefly noticeable in the landing gear, which, as a light construction having little head resistance, is perhaps good. But, as a landing gear, pure and simple, we doubt if anything more treacherous has ever been designed. As long as it is used only on smooth ground, it may stand up to its work all right-that is, if it were in may stand up to its work all right-that is, if it were in
the hands of a skilful pilot. What would happen over rough ground we dread to imagine. The chassis is all of steel, and there are only two laminations in the transverse spring.

There being no horizontal skid it is impossible to arrange the warping as heretofore. On this machine it is operated by bell cranks just below the fuselage; worked by the feet as usual. To cut down some of the head resistance of the Gnome engine, a dome is fitted over the front, a quarter segment of it being cut away to admit sufficien air for cooling. The wings only span 23 feet and they have noticeably less curvature and incidence than previous models. They are each stayed on the underside by four cables - two to each spar.

As regards the Hydravion, it has three floats Twostepped floats, supporting the body through a construetion of steel tubing form the main landing organs, and a

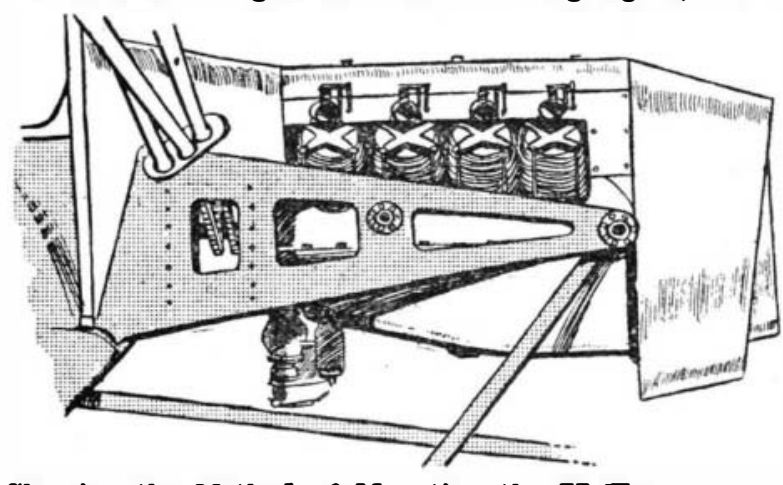

Showing the Method of Mounting the 75 Horse-power Renault Motor on the Savary Biplane.

\section{Enzymes and Inhibitants}

By A. Hardens, D.Sc., F.R.S.

IT has become apparent, as bio-chemical research ha progressed, that one of the devices employed by the living cell to regulate enzyme action, is the simultaneous production of an inhibiting substance which either totally" prevents the action of the enzyme or greatly modifles its intensity. Thus to take only a single example, in the yeast cell the powerful digestive enzymeyeast endotryptase - is accompanied by an anti-protease, in the presence of which the action of the enzyme is largely diminished. (Buchner and Haehn.)

These two antagonistic agents pass into the juice expressed from ground yeast and can be separated by boiling the liquid. The anti-protease being thermostable is unaffected, while the tryptase loses its activity.

A still more interesting case, in which the enzyme and inhibitant occur actually combined together ha been revealed by the researches of Dr. S. Hedin on Rennet, the results of which have recently appeared in a series of papers in Hoppe-Seyler's Zeitschrift.

Rennet is usually prepared by extracting the mucous membrane of the calf's stomach with dilute acid, and is then obtained in the form of a highly active solution. When, however, the extraction is made with cold water,

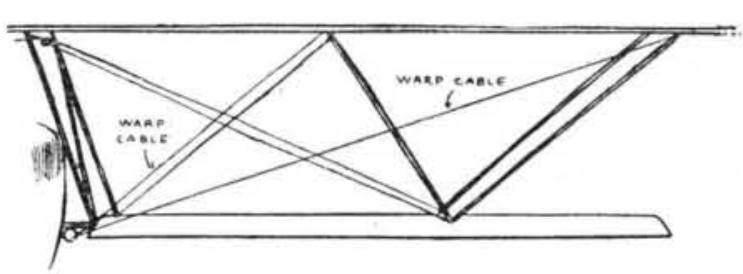

Bracing of the Planes of Clement-Bayard Biplane.

miniature egg-shaped float supports the tail. For the construction of the main floats cypress wood is employed. A peculiarity about these are the small fin-like projection that extend laterally from the front ends of each float They are so designed for a double purpose-to prevent the floats burying in a heavy sea, and to protect the propeller from spray. The propeller, by the way, is furthe armored at the tips. A change has been made in th building of the fuselage to strengthen it to withstand the heavier strains that landing in the water calls upon it to bear. In this machine, the ver tical struts in the body are of steel tubing, although the longitudinals and other portions of the body are still made of wood.

Two passengers can be accommodated in a wide sea immediately behind the pilot. He, the pilot, has before him, in addition to his controls and instruments, a start

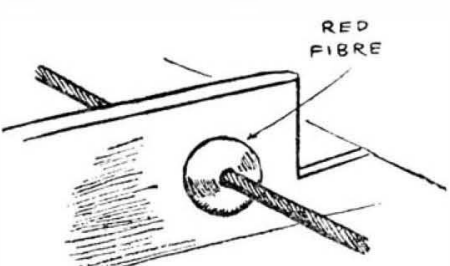

The Neat Control Wire Guide on the Nieuport Monoplane.

ing-handle, by which he can put the motor in motion without exterior help.

Since last year this firm do not seem to have changed their methods at all, and they remain almost the only firm of biplane manufacturers that have not been influenced by the monoplane trend in biplane design. Their present machine is fitted with a 75 horse-power Renault which is mounted in a rather neater manner than the

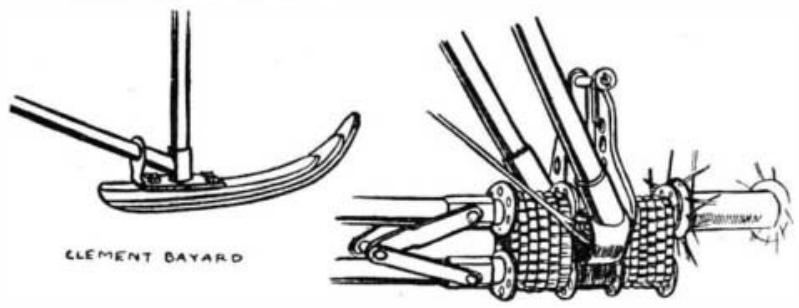

Two Details of the Clement-Bayard. On the Left the Rear Skid; on the Right the System of Shock Absorbers Employed in the Chassis.

engine on last year's machine. This point we illustrate. They are also showing, in a semi-finished state, a hydromonoplane, the chief peculiarities of which are that it has a metal torpedo body and that the wings are stayed from the floats by an haubannage of steel tubing.

$$
\text { R. E. P. }
$$

Among the hydro-monoplanes there is little doubt but that the R. F. P. two-seater is the favorite, partly because of its attractive appearance, but mainly because of the excellence that is shown in its construction and design

the solution ts found to possess only a slight degree of activity. If it be subsequently treated with dilute acid, however, it acquires a power of clotting milk equal to that of the extract made originally with acid. This phenomenon has been explained on the ground that the water extract contains an inactive mother-substance of the enzyme, or zymogen, which is converted by the action of the acid into the active enzyme. Hedin's experiments have, however, revealed the remarkable fact that this so-called zymogen is in reality a compound of the enzyme and an inhibitant, and that by suitable treatment either the active enzyme or the inhibiting substance can be obtained from it. It all appears sim ple enough, once we have the key to the situation.

By treatment with dilute acid the active enzyme is liberated and the inhibitant destroyed, while with dilute alkali (ammonia) the enzyme is rendered inactive and the inhibiting substance left free. When solutions containing the two antagonistic substances are mixed, combination again occurs, and when suitable proportions are used the resulting liquid has only a very slight clotting power.

A comparative study of the rennet enzymes of different animals has brought to light a still greater complication. Inhibiting substances can be also obtained from the extract prepared by water alone from the

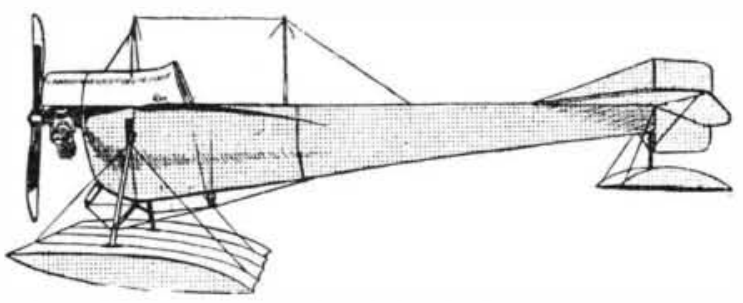

The 80 Horse-power R.E.P. Hydro-monoplane.

throughout. When resting on the water its main weight is sustained by one large Fabre float 10 feet wide, and measuring 8 feet from front to back. A single float seems to harmonize with the general appearance of a monoplane a great deal better than a pair of pontoon-like floats such as most of the other constructors fit. In assembling this float to the fuselage the same system of flexible suspension is made use of that is employed on the standard land machine. It is the only hydro-aeroplane shown at the Salon in which provision is made for the absorption of any shock that may be caused by landing suddenly upon the water. In addition to this, the construction of the Fabre float materially assists in deadening the shock. This, in fact, is M. Henri Fabre's chief claim for his floats, that they are flexible and give to a certain extent under the hammering influence of the waves. The bottom of his floats are covered with three-ply wood 5 millimeters in thickness. There are no transverse struts to support this, except one at the leading edge, for, were they fitted, it would render the float too solid for M. Fabre's liking. The top of the float is covered in with strong fabric, The top of the float is covered in with strong fabric,
tested to withstand a tension of 7,000 kilogrammes per square meter.

As for the remainder of the machine, it is purely standard in every respect, and remains one of the most notable examples of monoplane construction existing. It is interesting to mention that the machine shown on this stand is the identical one with which Molla carried off the first speed prize at the Tamise hydro-aeroplane meeting in Belgium some time since. It is equipped with an 80 horse-power Gnome engine.

zODIAC.

The Zodiac biplane has made no visible change at all since last year, except for the addition of a transparent shield above the pilot's and passengers' seat. Our sketches show this point, and also give a general idea of the machine.

It must be a wonderfully efficient biplane, for it must be no mean weight, and it does all sorts of passenger-carrying work with a 50 horse-power Gnome engine. The high aspect ratio of its planes must be responsible for this, as well as the saving in head resistance of a neat and clean chassis.

(To be continued.)

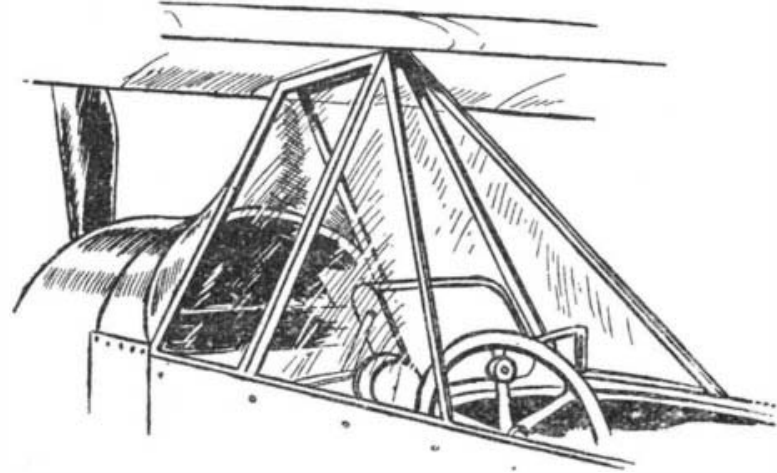

The Pilot's Seat of the Zodiac Biplane, Covered in With Non-inflammable Celluloid to Protect the Occupant.

stomach membrane of the pig, the guinea pig, and the pike precisely in the same way as from the calf. Fach of these inhibitants when added in suitable amount to the rennet prepared from the same animal completely removes its power of clotting milk. When, however, the inhibitant from one animal is added to the active rennet from another animal, the inhibitant from the guinea pig for example to calf's rennet, or the inhibitant from the calf to guinea-pig's rennet, no inhibition whatever occurs-the relation of inhibitant to rennet is strictly specific. It follows from this that both the enzyme and its inhibitant are different for each animal, a fact of great interest and importance. In spite of this difference, however, all these enzymes are equally capable of clotting cow's milk. It appears, therefore that identity of action upon a given substance is not unficient ground for the conclusion that two enzymes are identical. In most cases, however, this evidence is all that is available. The invertase from each of the different yeasts, bacteria, molds, etc., which contain it, is usually regarded as but one enzyme because it exerts the characteristic effect on cane sugar. In the light of Hedin's experiments this can no longer be assumed, the probability would indeed rather appear to lie in the direction that each of these is a distinct substance -The Chemical World. 